\title{
ERRORS INVOLVED IN RADIOLOGICAL HEART VOLUME DETERMINATION BY THE ELLIPSOID-APPROXIMATION TECHNIQUE
}

\author{
BY \\ D. W. EVANS AND P. B. CARPENTER \\ From the Queen Elizabeth Hospital, Birmingham \\ Received October 12, 1964
}

The radiological measurement of the heart's volume during life has been attempted by modelmaking (Palmieri, 1929), tomographic (Fuchs and Bayer, 1953), and simple formula techniques. The latter depend upon the assumption that the shape of the heart approximates to that of some regular figure, estimates of its volume then being obtainable from measurements of the heart's shadows in orthodiagraphic or teleradiographic projections. The simplest such assumption is that which considers the heart as a sphere, and on this basis volume estimates can be made from measurement of a single projection of the heart (Geigel, 1914). These estimates are unsatisfactory, however, chiefly because the heart's depth bears no constant relation to the dimensions of its postero-anterior projection (Ludwig, 1939).

Two orthodiagraphic projections at right angles to each other (frontal and sagittal) were used by Rohrer (1916/17) and Kahlstorf (1932), who based their volume estimates on planimetric and linear measurements and the assumption that the heart's shape is betwixt that of an ellipsoid and a paraboloid. Subsequently it has been usual to make only linear measurements of teleradiographic projections (Jonsell, 1939; Liljestrand et al., 1939), basing the estimates on the assumption that the heart's configuration is ellipsoidal.

The use of teleradiographic projections demands the incorporation in the formula of a correction for magnification. This is conveniently made by the method of triangles, the theoretical objection that the divergent beam does not project the heart at the extremities of its axes being of no practical importance (Blasius, 1938).

Comeau and White (1939) thought the Palmieri modelling technique to be the best available for measurement of heart volume during life but, like more recent modifications (Takahashi and Shinozaki, 1954), it involves too much expenditure of time, and too much irradiation of the patient, for routine use. Similar criticisms apply to the tomographic techniques, estimates from which have been compared with estimates provided by several formula methods (Broustet et al., 1960). The ellipsoid-approximation formula method has proved satisfactory during some 30 years of use in Sweden, and has also been found valuable for clinical studies in this country (Domenet, Evans, and Howarth, 1963). The need for estimates of heart volume as part of a research project led to an appraisal of the errors involved in the ellipsoid-approximation method, with a view to determination of the significance of measured differences.

The first source of error requiring assessment was the obvious fact that most human hearts are not ellipsoidal in shape. The less closely a heart approximates to an ellipsoid, the more inappropriate is the formula: $V=\pi / 6 . M \cdot 1 . \mathrm{b} . \mathrm{d}$ 
for derivation of its volume $V$ from measurements of the long and broad axes ("l" and " $b$ ") of its postero-anterior projection and of the horizontal diameter (" $\mathrm{d}$ ") of its lateral projection; $M$ is a factor included to account for magnification and is also likely to be inappropriate where a heart's contour is grossly irregular. Spatial orientation of the figure is immaterial in application of this formula to a true ellipsoid (Kahlstorf, 1932) but backward tilting of a non-ellipsoidal heart may affect estimation of its volume by this technique.

A second obvious source of error arises from the impossibility, in many cases, of measuring true major and minor axes of the cardiac "ellipse" (postero-anterior projection). A third concerns the likelihood of considerable observer-variation in making the necessary axis measurements, and others include the real changes in heart size that occur during the cardiac and respiratory cycles. Minor variations in radiographic technique on different occasions also require consideration.

The first two sources of error were assessed on the basis of evidence provided by a post-mortem study involving direct determination of the heart's volume by displacement after radiographing the cadaver for the purpose of radiological heart volume estimation. Observer-variation was assessed by comparison of repeated measurements of 30 pairs of films by two observers. Cyclical variations in estimated heart volume were separately evaluated and their importance in regard to volume estimates based on random-exposure films was also assessed.

\section{MATERIAL AND METHODS}

(a) Post-mortem Study. Thirty-two cadavers were $\mathrm{x}$-rayed, using a portable $\mathrm{x}$-ray unit and approximately in-life factors, for the purpose of radiological heart volume determination. $2 \mathrm{~m}$. postero-anterior and $1.5 \mathrm{~m}$. (grid) left lateral films were taken of the erect, suspended bodies, centering on the estimated position of the heart. Rigor mortis was present at the time in all cases. Heart volume estimates were made from the films (Fig. 1) using axis measurements ( $1, b$, and d) based on reference points agreed by two or more observers. The long axis (l) of the cardiac "ellipse" (P-A projection) usually coincided with the line joining the cardiac apex to the point of junction of the right heart border and great vessel shadow. The short axis (b) was

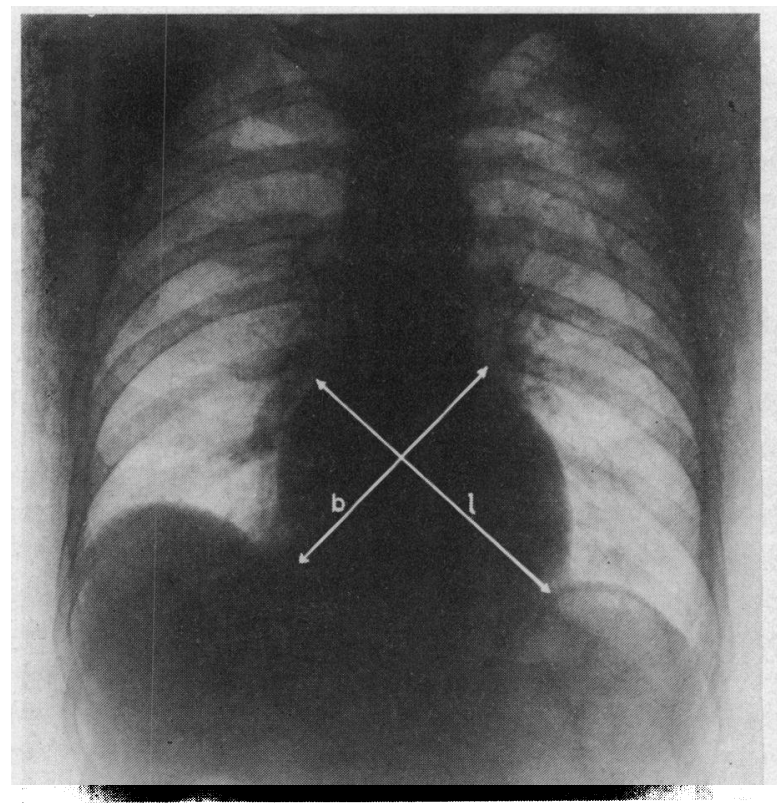

A

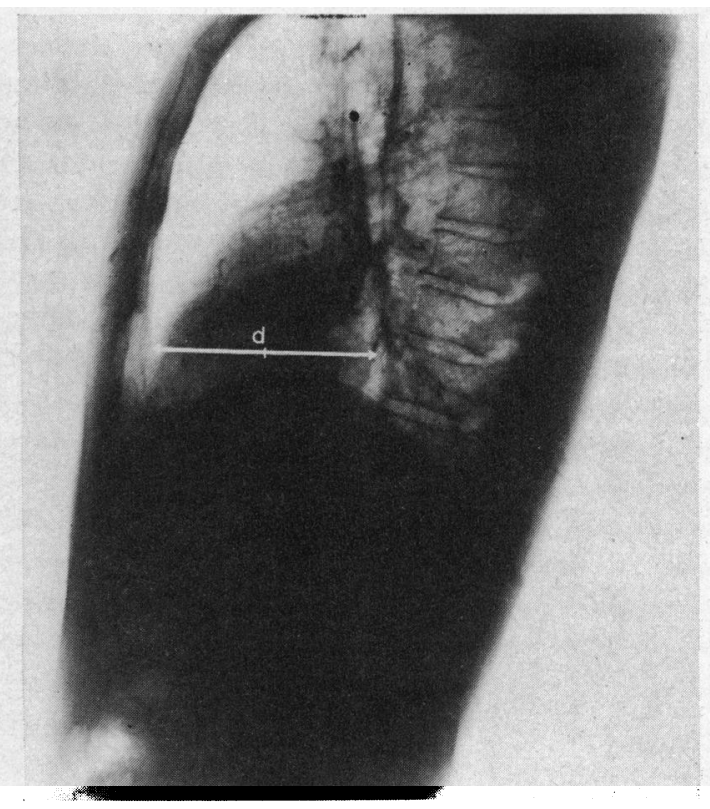

B

FIG. 1.-Post-mortem chest radiographs of a 61-year-old hypertensive man showing axes "l" and "b" of cardiac ellipse in P-A projection (A) and axis "d" drawn on left lateral film (B). 
drawn less rigidly between fixed points than hitherto (Domenet et al., 1963) because in many cases it was found possible to measure such an axis more nearly at right angles to " 1 " by first making a short extrapolation of the right lower cardiac contour and joining this by a straight line to the junction of pulmonary conus and left heart border. Such licence seemed theoretically desirable in so far as the basic assumption concerned true major and minor axis measurements of (a projection of) the heart considered as an ellipsoid. " $\mathrm{d}$ " was measured as the horizontal diameter of the cardiac "ellipse" as seen in the left lateral projection.

At first the factor $(0.41)$ found appropriate to the in-life situation (Domenet et al., 1963) was used for $\pi / 6 . M$ in the volume formula. Subsequently it was appreciated that the centre-of-heart to film distances were shorter in this post-mortem series, mainly on account of wasting. Re-estimates of heart volume were, therefore, made using individually-calculated magnification factors $(M)$ based on centre-of-heart to skin distances (which are themselves slightly magnified), measured from the films and skin to film distances of $1 \mathrm{~cm}$. (P-A) and $2 \mathrm{~cm}$. (lateral), respectively. $M=\left(\frac{200-a}{200}\right)^{2} \cdot \frac{150-c}{150}$, where "a" and "c" are the centre-ofheart to film distances appropriate to the P-A and lateral projections respectively (Fig. 2).

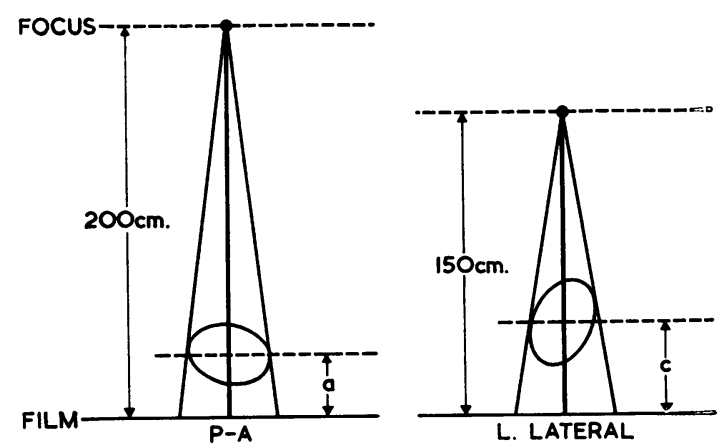

Fig. 2.-Non-scale diagrams showing focus-film distances and heart-film distances (a and c) used in making magnification correction.

At necropsy, usually the following morning, the heart was dissected out and its great vessels ligated close to their site of origin or entry. Before tying the final left-sided and right-sided ligatures, the chambers of the heart were filled with water, except in two cases in which the chambers were already full of clot. Care was taken to ensure that the heart was not overfilled under pressure, and the final ligatures were tied with the heart lying on the necropsy table and with water filling each vessel stump to the brim. Refilling experiments showed the difference in volume between obvious underfilling and as much overfilling as the ligatures would tolerate to be only about $30 \mathrm{ml}$. The appearance of the water-filled hearts was similar to that of the clot-filled hearts.

The volume of the filled heart was determined by displacement using a simple system capable of giving duplicate readings within $10 \mathrm{ml}$. In this way the displacement volumes of 28 cadaver hearts were determined. In the other 4 , technical difficulties defeated attempts at dissection and filling.

In 8 of the 28 cases for which displacement heart volumes were available, technical imperfections or heavy paracardiac shadows prevented complete agreement between the observers on the points to be used for the axis measurements. These 8 were, therefore, excluded from further consideration, though wherever individual observers thought meaningful radiological estimates possible they proved as close to the displacement volume figures as in the 20 cases forming the basis of the major comparison.

The final 20 cases comprised 9 male (age range 17 to 74 years) and 11 female subjects (39 to 78 years). Six of them had normal hearts. Of the remainder, 5 had coronary artery disease (one with hypertension also), 5 had hypertension, 3 had congenital heart disease, and 2 had rheumatic heart disease. One (Case 13) had localized aneurysmal dilatation of the left ventricle; otherwise there was no grossly misshapen heart in this series.

(b) Observer Variation. 30 pairs of films $(2 \mathrm{~m} . \mathrm{P}-\mathrm{A}$ and $1.5 \mathrm{~m}$. left lateral) taken for the purpose of heart volume determination during life were randomly numbered. Each of two observers then made axis measurements and heart volume estimates (assuming $\pi / 6 . M=0 \cdot 41$ ) from these films which were selected only 
in so far as they included no gross pleural effusions or other paracardiac shadows precluding repeatable measurement. Some hours later, after the identifying numbers had been interchanged, each observer remeasured the films and made a second volume estimate in each case. All the hearts in this series were abnormal, 20 of them being the seat of rheumatic carditis, 3 of coronary disease, 3 of congenital defect, 2 of hypertensive disease, and 2 of thyrotoxic heart disease. 16 of the patients concerned were women and 14 were men.

(c) Cardiac Cycle Variation. Standard end-inspiratory P-A and left lateral cardiac volume films were taken at chosen phases of the cardiac cycle in 25 patients with normal sinus rhythm. A triggering device permitted x-ray exposures coinciding with the first part of the $\mathbf{P}$ wave in the electrocardiogram (diastolic films) or with the second half of the $T$ wave (end-systolic films). Choice of these times was based on the work of Hubacher and Nyffeler (1946), Ruosteenoja and colleagues (1958), and Plas and Pallardy (1963). Voltage pulses fed back into the electrocardiograph from an ionization chamber in the path of the x-ray beam confirmed the moments of exposure. The duration of each exposure was as short as possible, being approximately $0.04 \mathrm{sec}$. for the P-A film and $0.06 \mathrm{sec}$. for the grid lateral. Skin-cassette distances were measured in each instance to permit the more accurate calculation of magnification factors. "Systolic" and "diastolic" heart volume estimates were made from the respective film pairs; to ensure measurement of similar axes in both systole and diastole, the two P-A and two lateral films were directly compared at the time of measurement.

Twenty pairs of heart volume estimates (10 normal hearts and 10 abnormal hearts) proved acceptable in regard to placing of exposures, and on these the assessment of diastolic/systolic variation is based. Eleven of the patients concerned were men (age range 23 to 61 years) and 9 were women (21 to 60 years). Of the 10 patients with abnormal hearts, 5 had hypertension, 2 had aortic stenosis, 1 had mitral stenosis, 1 an atrial septal defect, and 1 coronary artery disease. None was in heart failure at the time of the study.

(d) Respiratory and Technical Variation. Pilot studies on normal and abnormal subjects showed expiratory films to be quite unsuitable for heart volume determination (and, of course, for routine reporting). In accordance with the practice of Axén, Lindgren, and Malmström (1946), Amundsen (1959), and Plas and Pallardy (1963), therefore, the $x$-ray exposures were made immediately after deep inspiration. To assess the possible influence on volume estimates of minor variations in diaphragm height or formes frustes of the Müller and Valsalva manœuvres (Natvig, 1934), duplicate end-inspiratory films (P-A and left lateral) were taken in 13 instances. In 3 of these (two male subjects with normal cardio-respiratory systems and one very dyspnœic man with emphysema) each exposure was triggered at a fixed interval, by the first QRS complex after the instruction to stop breathing. In the other 10 cases $(7$ normal hearts, 1 rheumatic, 1 coronary, and 1 pulmonary heart disease) cardiac cycle variation was not excluded, exposures being made at random in this respect but always within a few seconds of end-inspiratory apnœa. A few minutes sometimes elapsed between the duplicate exposures, but absence of significant change in pulse rate suggested maintenance of a reasonably steady state in these erect, inactive, subjects. Re-posturing was necessary before each exposure so that duplicate heart volume determinations on the basis of these films also provided a check on radiographic technique.

\section{RESULTS}

(a) Post-mortem Study. The results of the comparison between radiological heart volume $(\pi / 6 . M=0.41)$ and displacement heart volume in the final 20 cases are shown in Table I and Fig. 3. The range of error, comparing the x-ray estimates with the displacement volumes, was from -125 $\mathrm{ml}$. to $+67 \mathrm{ml}$. The algebraic mean error was $-22.6 \mathrm{ml}$. and the standard deviation of the differences $47.8 \mathrm{ml}$. The mean $\mathrm{x}$-ray estimate $(761.0 \mathrm{ml}$.) was not significantly different from the mean displacement volume $(783.5 \mathrm{ml}$.). There was no correlation between heart size and accuracy of estimate. The numbers were too small to allow conclusions to be drawn regarding any possible relation between type of heart disease and accuracy of estimate.

Re-estimation of radiological heart volume using the greatest horizontal depth measurement of the lateral projection as " $\mathrm{d}$ " made no appreciable difference to the accuracy of the estimates. Reestimation using the composite method of measuring " $b$ " (Ungerleider and Gubner, 1942) was also attempted; in 8 instances a high diaphragm caused gross underestimation of " $b$ " on the basis of perpendiculars (to "l") drawn from the cardio-phrenic recess and pulmonary conus, and in the 
TABLE I

Comparison of Post-Mortem Radiological Heart Volume Estimates $(\mathrm{K}=\mathbf{0} \cdot 41)$ and Heart Volumes by DISPLACEMENT

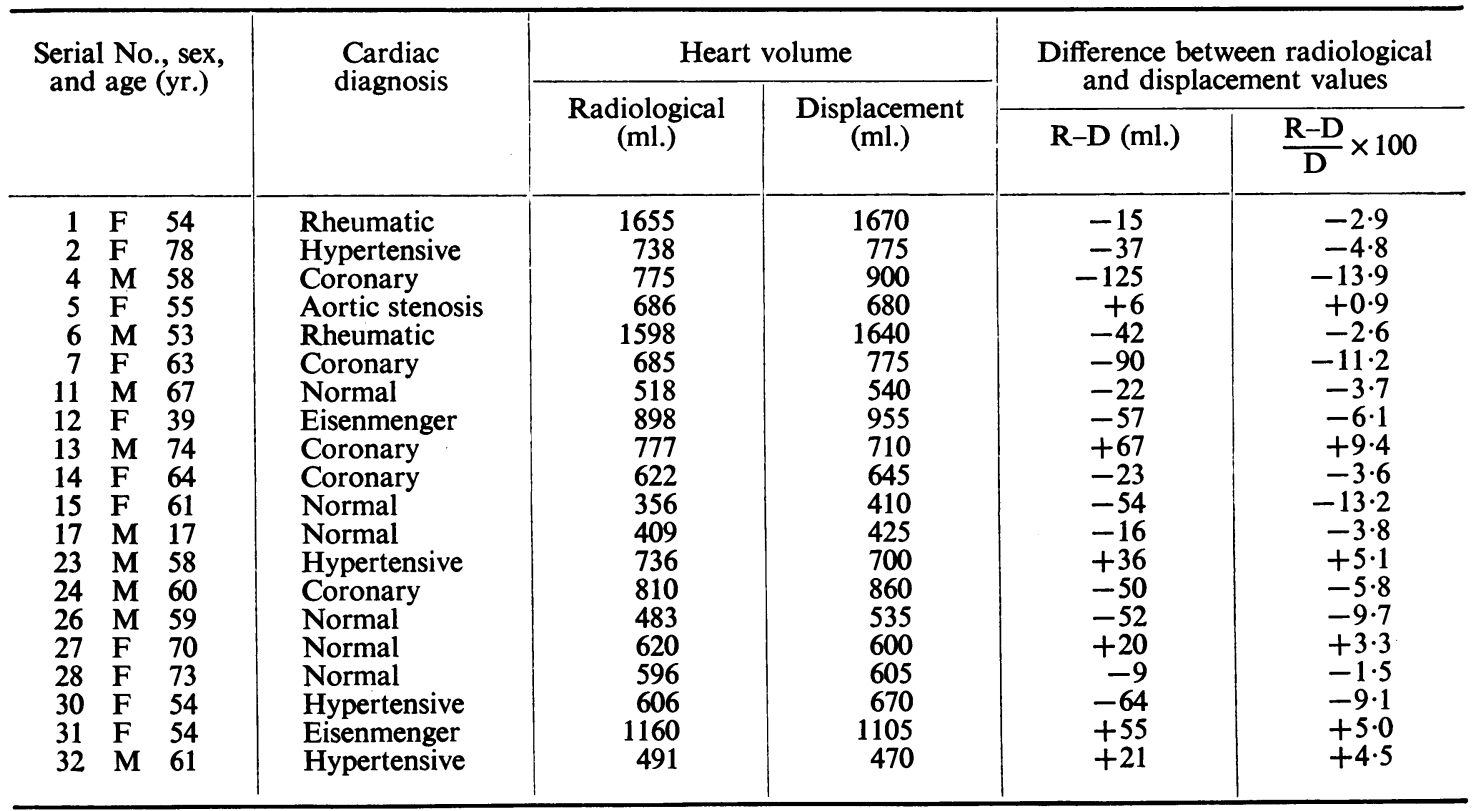

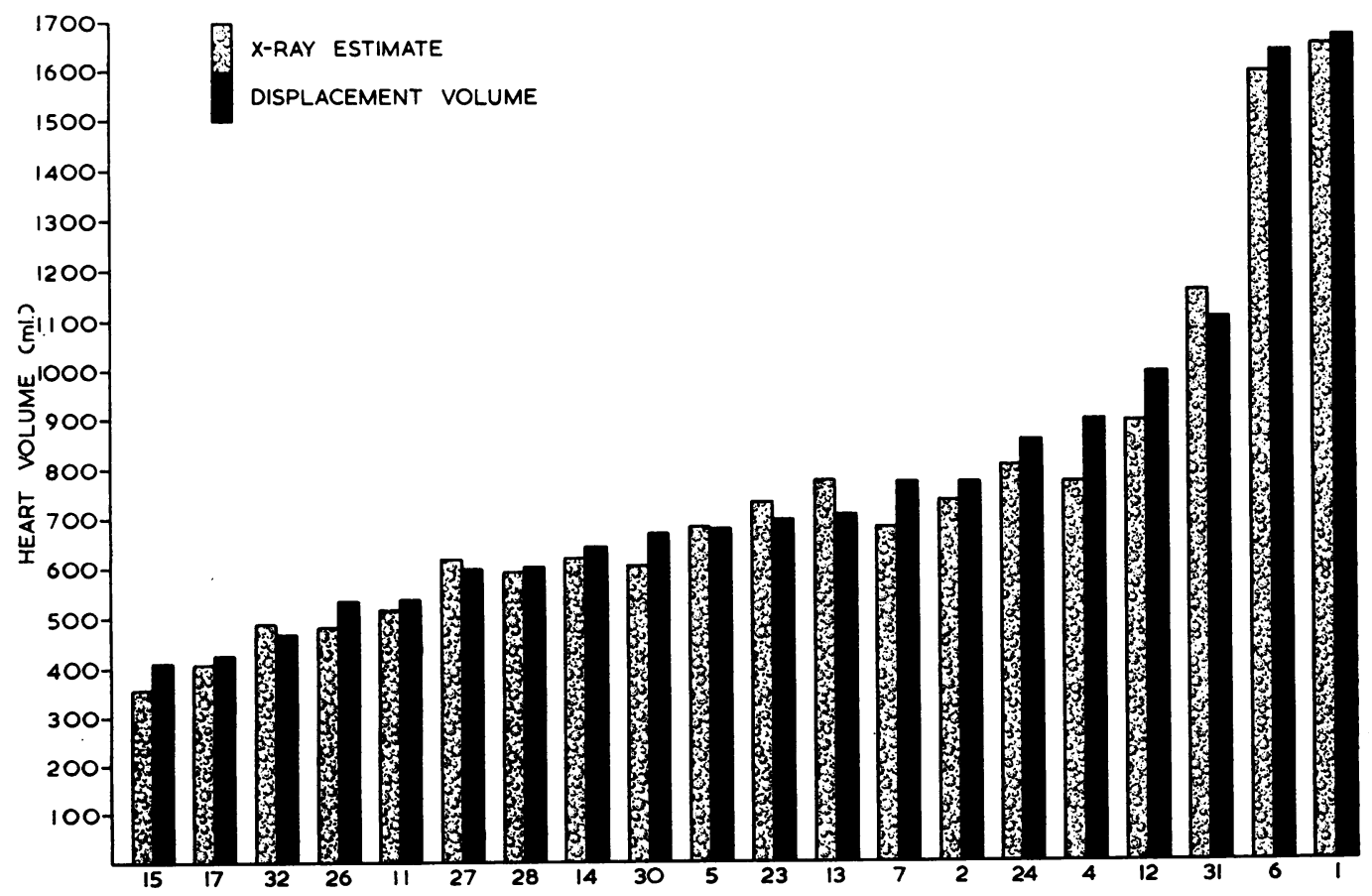

SERIAL NUMBER

FIG. 3.-Comparison of post-mortem radiological estimates $(K=0.41)$ and displacement heart volumes in 20 cases. 


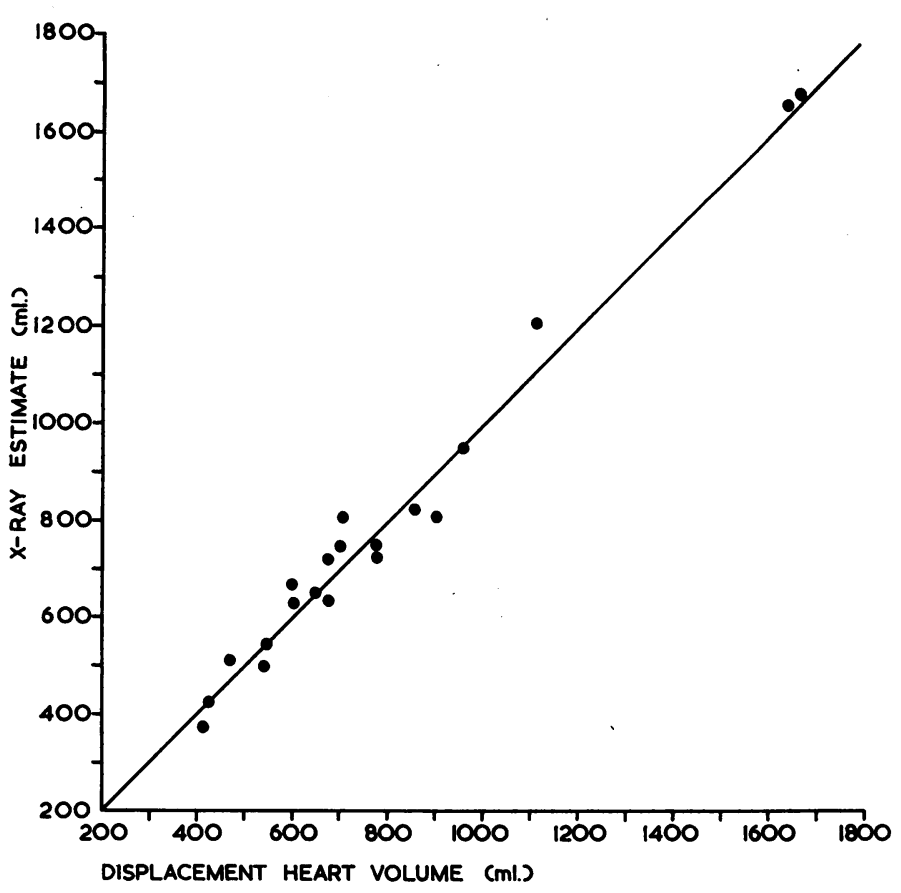

FIG. 4.-Post-mortem radiological estimates (individually calculated magnification corrections) versus displacement heart volumes.

remaining 12 cases composite " $b$ " measurements yielded volume estimates within 6 per cent of those from direct " $b$ " measurement. As suggested by Jonsell (1939), minor degrees of obliquity of the simply-measured axes appear to be practically unimportant.

Recalculation of the radiological estimates using individually calculated magnification corrections did not materially alter the range of error $(-91 \mathrm{ml}$. to $+102 \mathrm{ml}$.) but reduced the algebraic mean error to $+7 \cdot 2 \mathrm{ml}$. (S.D., $50 \cdot 1 \mathrm{ml}$.). Fig. 4 shows the correspondence between these radiological

TABLE II

ObServer Error in Estimating Heart Volumes

Range of Estimated Heart Volumes 326-4144 ml. (Mean $1490 \mathrm{ml}$.)

\begin{tabular}{|c|c|c|c|c|c|}
\hline & $\begin{array}{l}\text { Pairs of } \\
\text { estimates }\end{array}$ & $\begin{array}{l}\text { Range of } \\
\text { differences }\end{array}$ & $\begin{array}{l}\text { S.D. of } \\
\text { differences }\end{array}$ & $\begin{array}{l}\text { Algebraic mean of } \\
\text { differences } \pm \text { S.E.m.m }\end{array}$ & $\begin{array}{l}\text { S.D. of } \\
\text { estimates }\end{array}$ \\
\hline $\begin{array}{l}\text { Difference between two } \\
\text { estimates of Observer } \\
1 \text { (2nd estimate-1st } \\
\text { estimate) . . .. } \\
\text { Difference between two } \\
\text { estimates of Observer } \\
2 \text { (2nd estimate-1st } \\
\text { estimate) ... .. } \\
\text { Difference between } \\
\text { estimates of Observer } \\
2 \text { and Observer } 1 \text { on } \\
\text { same film .. . . }\end{array}$ & 60 & $\begin{array}{l}-144 \text { to }+286 \mathrm{ml} \text {. } \\
-188 \text { to }+99 \mathrm{ml} \text {. } \\
-218 \text { to }+261 \mathrm{ml} \text {. }\end{array}$ & $\begin{array}{l}79 \cdot 1 \mathrm{ml} . \\
62 \cdot 2 \mathrm{ml} . \\
90 \cdot 1 \mathrm{ml} .\end{array}$ & $\begin{array}{l}+20 \cdot 9, \pm 14 \cdot 4 \mathrm{ml} \\
-17 \cdot 9, \pm 11 \cdot 4 \mathrm{ml} \\
+34 \cdot 3, \pm 11 \cdot 6 \mathrm{ml}\end{array}$ & $\begin{array}{l}57.0 \mathrm{ml} \text {. } \\
45.0 \mathrm{ml} \text {. }\end{array}$ \\
\hline
\end{tabular}

S.D. =standard deviation; S.E.m =standard error of the means. 
estimates and the displacement volumes. The mean factor $K(\pi / 6 . M)$ for the post-mortem series thus proved to be 0.426 (range, 0.412 to 0.441 ).

(b) Observer Variation. The results of analysis of the observers' differences are shown in Table II. The standard deviations of the estimates, where each observer's second estimate is compared with his first, are calculated according to Snedecor (1952). Observer 1 (D.W.E.) tended to vary more in his measurements of larger hearts $(0.02<\mathrm{p}<0.05)$, but the radiologically-trained Observer 2 (P.B.C.) showed no such tendency. Observer 2 made significantly larger $(\mathrm{p}<0.01)$ volume estimates from the same films than Observer 1 , and this proved to be due to a tendency to measure longer axes "b". This finding led to the discovery that, whereas Observer 1 rarely made any extrapolation of the right lower cardiac contour, Observer 2 freely extrapolated this border in his attempt to measure " $b$ " more nearly at right angles to "l". Though he was not, of course, permitted to mark the films for this purpose, he appears to have been at least as consistent as Observer 1 in his re-measurements in spite of (or perhaps because of) this licence.

Occasional large errors must evidently be expected when moderately experienced observers re-measure a series of routine cardiac volume films. In 24 and 25 instances out of 30, respectively,

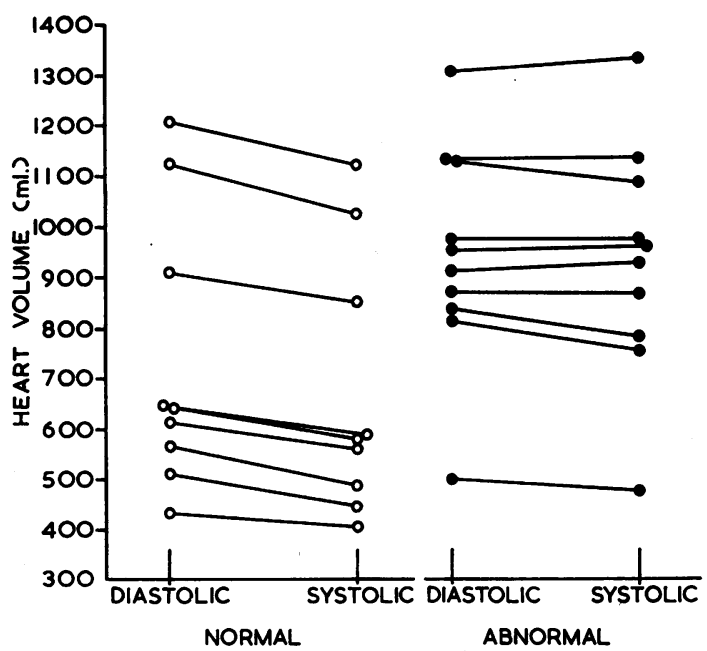

Fig. 5.-Effect of phase of cardiac cycle upon radiological volume estimates for normal and abnormal hearts.

however, the observers' second volume estimates were within 5 per cent of their first. No analysis of the influence of film quality on observer variation was possible because there was an insufficient measure of agreement between the observers in grading the films.

(c) Cardiac Cycle Variation. The diastolic/systolic estimate variation is shown graphically in Fig. 5. For the 10 normal hearts (mean estimated volume, $745 \mathrm{ml}$.), an algebraic mean volume change of $-66 \cdot 1 \mathrm{ml}$. (range, $-28 \mathrm{ml}$. to $-93 \mathrm{ml}$.) was recorded, decrease in estimated volume with systole being given a minus sign. This mean systolic decrease is highly significant $(p<0.001)$. For the 10 abnormal hearts (mean volume, $947 \mathrm{ml}$.), the algebraic mean change was $-12.0 \mathrm{ml}$. (range, $-54 \mathrm{ml}$. to $+30 \mathrm{ml}$.), and this is not significant.

No significant change in axis " $\mathrm{d}$ " occurred with systole. The greatest changes were seen in the length of axis " $b$ ", as previously noted in recumbent normal subjects by Ruosteenoja and colleagues (1958). The range of factors $K(\pi / 6 . M)$ found in this series was from 0.396 to 0.425 (mean, 0.414 ), the mean left axilla-film distance being $3 \cdot 2 \mathrm{~cm}$. This finding compares with the mean in-life factor $K$ of 0.41 previously found (Domenet et al., 1963), assuming a constant left axilla-film distance of $3.5 \mathrm{~cm}$. 
(d) Respiratory and Technical Variation. No material difference in estimated heart volume was found between the duplicate end-inspiratory determinations, with exposure at the same moment in the cardiac cycle, in the two subjects with normal cardio-respiratory systems. In the emphysematous patient, the two estimates differed by $74 \mathrm{ml}$. (6.9\% of the first estimate) and this difference probably reflects the difficulty experienced by the subject in returning to, and holding, the same inspiratory position.

In the 10 random exposure (with regard to cardiac cycle) duplicate determinations only three differences greater than $18 \mathrm{ml}$. $(2 \cdot 8 \%)$ were found. In these three cases, obvious changes in heart shape suggested that systole had been encountered in one or other exposure. The maximum difference in these estimates was $67 \mathrm{ml} .(12 \cdot 1 \%)$. In two other cases there were small but obvious differences in diaphragm level in the duplicate P-A films; these minor respiratory differences appear to have exerted no appreciable influence on the repeatability of the estimates. The mean difference for all 10 pairs of estimates was $7 \cdot 6 \mathrm{ml}$. (S.D., $21 \cdot 8 \mathrm{ml}$.).

\section{Discussion}

The post-mortem study, in common with that of Friedman (1951), suggests that the ellipsoidapproximation assumption is applicable, for the purpose of over-all volume estimation, to the great majority of dead human hearts. No heart of bizarre configuration was encountered in this study, though subjects were unselected save in regard to technical suitability and the absence of disqualifying pericardial effusion. Use of the principle for determination of heart volume in life involves the further assumption that the shape of the dead heart is similar to the mean (diastolic) shape of the living heart. Radiological experience, and direct inspection of the heart at thoracotomy, suggests that this is so even though the heart commonly contracts by some 30 per cent after death (personal observations and those of Friedman, 1950).

The close correspondence of the post-mortem radiological estimates and displacement heart volumes also gives confidence in the methods of axis measurement and magnification correction. Backward tilting of the heart in the body is evidently of little practical importance, even though the heart is not truly ellipsoidal. From these considerations it appears that the technique is basically capable of yielding reasonably accurate heart volume estimates in life, though it would clearly be wrong to apply the principle in cases where the heart shape deviates very grossly from ellipsoidal.

The observer variation study indicates the extent to which moderately experienced observers may differ in making the volume estimates from the same routine films of subjects with diseased hearts. Because individual observers may show small consistent differences with each other, as a result of personal preferences in regard to measuring technique, chief interest centres upon the reproducibility of estimates by the same observer re-measuring the films in isolation. In this trial, where the mean estimated heart volume was $1490 \mathrm{ml}$, the difference between two estimates by Observer 1 necessary to infer (at the $95 \%$ probability level) real difference in the films measured was found to be $161 \mathrm{ml}$.; for Observer 2 this difference was $127 \mathrm{ml}$. Such potential observer variation may evidently be of great importance in applying the method to the measurement of changes in heart volume. Experience of the method, and perhaps the use of films of superior quality, is probably responsible for the more consistent re-measurement reported by Axén and colleagues (1946); the performance of these authors, measuring films of normal hearts (mean estimated volume, $797 \mathrm{ml}$.), suggests that the expert observer can infer real differences when estimates differ by $70 \mathrm{ml}$.

Of the three axes, "l" is most consistently and " $d$ " least consistently re-measured in ordinary routine films. Difficulty arises in measuring " $d$ " when the film is not a true lateral and when some part of the heart shadow may appear to lie behind the barium-filled œsophagus or in front of the inner border of the sternum. Measurement of " $b$ " is likely to be more consistent when the experienced observer completes the cardiac ellipse in his mind's eye and draws " $b$ " as nearly perpendicular to "l" as possible, from the pulmonary conus/left heart junction to the extrapolated right lower cardiac contour. To accord with the theoretical basis of the method, "l" must also be drawn 
as the long axis of the cardiac ellipse, rather than too rigidly from defined points. Where the relevant points of the cardiac contour are obscured by paracardiac shadows, it must be accepted that reliable heart volume estimation is impossible.

The possibility of observer variation when films are measured in isolation on one occasion only is so great that small but obvious differences in heart size could not be reliably described by this method. To overcome this difficulty in the description of changes in estimated heart volume during the cardiac cycle, and as an alternative to multiple re-measurements of films in isolation over a long period, measurement of directly compared films was employed. This technique ensures that similar axes are measured in each pair of films so that minor changes in the axis measurements are not masked. Use of this technique introduces the possibility of observer bias in so far as it might be possible to exaggerate changes in heart size, when these are obvious on superimposition of the films, by preferential measurement of axes showing most change. An assessment of this possibility showed the choice of legitimately measurable axes to be so limited that such preferential measurement exerted no appreciable influence on a series of duplicate determinations of this kind.

The diastolic/systolic differences found for normal hearts (28 to $93 \mathrm{ml}$.) compare with Jonsell's (1939) range of 60 to $150 \mathrm{ml}$., the technique and exposure times being essentially similar in both series. The mean difference $(33 \mathrm{ml}$.) found by Ruosteenoja and colleagues (1958) in recumbent normal subjects is smaller than the mean difference $(66 \mathrm{ml}$.) for the erect subjects of this normal series, but technique may have differed in other important respects besides that of posture. The measured diastolic/systolic differences cannot, of course, be used in the measurement of stroke volume, as claimed by Hubacher and Nyffeler (1946), because change in heart shape may alter the applicability of the basic ellipsoid assumption and because venous return continues during systole.

There appears to be much less diastolic/systolic volume variation where diseased hearts are concerned and in several cases there was no detectable change within the limits of error of the method. Random x-ray exposure, in regard to cardiac cycle, is, therefore, less likely to diminish repeatability of estimates in cases of heart disease than in health. The chance of such random exposures being made during systole is, however, not altogether negligible as the small series of duplicate determinations from unsynchronized exposures shows. This effect of cardiac cycle changes on the heart volume estimates is probably the most important aspect of the "technical error" when radiographic technique is good, but in very dyspneic subjects respiratory variation may also be important.

With similar posture and centering, diaphragm height provides a ready visual check on the comparability of inspirations when repeat determinations are made on the same subject. It is also possible, from inspection of the left lateral film, to check that the patient has not been allowed to straighten up before this exposure. The importance of obtaining true lateral views, for accurate measurement of " $\mathrm{d}$ ", has already been mentioned. Experiments carried out with synchronized exposures indicate that beam-centering is not critical, the axis measurements being unaffected by centering on the fourth dorsal spinous process or on the heart's centre.

Apart from these purely technical considerations, the comparability of duplicate determinations at remotely different times involves other variables such as heart rate, venous return, and cardiac output. Such influences may be more important when films are taken in the erect than in the recumbent posture (Larsson and Kjellberg, 1948; Musshoff and Reindell, 1956). An assessment of the influence of rate changes was carried out in one subject fitted with an artificial pacemaker. In this man, reduction in heart rate from 90 to 60 per minute did not significantly affect the estimate of heart volume from electrocardiogram-synchronized exposures but an increase from 90 to 120 per minute reduced the estimated volume by $41 \mathrm{ml}$. $(5 \cdot 2 \%)$. It may be helpful, in assessing the significance of volume changes over a period, to note the heart rate prevailing at the time of each determination and to ensure that the subject be given time to achieve a reasonably steady state (in the standard posture) before the films are taken.

These latter considerations are not strictly relevant in the context of the error of the method since they concern real non-cyclical changes in heart volume, albeit of an acute nature. The over-all error of the method itself may best be described by combining (in a " $t$ " test) the small technical error 
and the greater possibility of observer variation. On this basis, and assuming similar applicability of the ellipsoid-approximation assumption on both occasions, we find that measured changes of approximately $160 \mathrm{ml}$. are indicative (at the $95 \%$ probability level) of real non-cyclical change in heart volume. An expert observer (Axén et al., 1946) may be able to attach similar significance to measured changes of approximately $105 \mathrm{ml}$. These figures refer to the measurement, in isolation, of random exposure films. The relation between the measured volume changes and the real changes in volume will be close only when the heart conforms closely to the basic ellipsoid assumption on both occasions. In most cases, where the heart shape does not change obviously, the discrepancy is likely to be a matter of the same simple proportion at each determination.

Where volume estimates on two different hearts are concerned, or where heart shape changes obviously between examinations, an additional variance must be introduced in determining the significance of measured changes. Assuming that, at ordinary rates, the "mean heart shape" is diastolic and that this shape is similar to that of the dead heart, the variance found from the post-mortem study may be included to allow for individual differences in applicability of the basic assumption. Hence we find that measured differences of approximately $210 \mathrm{ml}$. may be considered significant, at the 95 per cent probability level, of real but not necessarily chronic changes in over-all heart volume.

\section{SUMMARY}

Post-mortem evidence indicates that the basic assumption involved in the ellipsoid-approximation technique is applicable to the great majority of human hearts.

The biggest potential error involved in heart volume estimation in life by this technique is observer variation in making the axis measurements from the $\mathrm{x}$-ray films. When this error is combined with technical error (including that imposed by cardiac cycle changes) it is found that measured differences of $160 \mathrm{ml}$. or more are significant $(\mathrm{p}<0.05)$ of real volume change in an individual heart, and that differences of $210 \mathrm{ml}$. or more similarly signify real differences in the volumes of two different hearts.

Axis " $b$ " is best simply measured, from the junction of pulmonary conus and left heart border, as nearly perpendicular to " $\mathrm{l}$ " (the long axis of the cardiac ellipse) as possible; to facilitate this measurement some extrapolation of the right lower cardiac contour is permissible. " $\mathrm{d}$ " is best measured as the horizontal diameter of the cardiac ellipse as seen in the lateral projection.

With erect subjects, $2 \mathrm{~m}$. postero-anterior and $1.5 \mathrm{~m}$. left lateral focus film distances, and skinfilm distances of approximately $0.5 \mathrm{~cm}$. and $3.5 \mathrm{~cm}$. respectively, reasonably accurate estimates of over-all heart volume $(V)$ are provided by the formula:

$$
V=0 \cdot 41.1 . \mathrm{b} . \mathrm{d}
$$

The method is unsuitable for use where the heart is of bizarre configuration, where the relevant parts of its contour cannot be clearly seen in the x-ray films, and where the subject is too dyspnœic to maintain the full inspiratory position for a few seconds.

Our thanks are due to Dr. O. E. Smith and the staff of the X-ray Department, Queen Elizabeth Hospital, to Dr. J. A. Newell who built the exposure synchronizing device, to Dr. R. F. Fletcher for much help with the statistical analysis, and to Drs. O. Brenner, P. H. Davison, and others for allowing us to study patients under their care.

The data from this study form part of an M.D. thesis submitted by one of us (D.W.E.) to the University of Wales.

\section{REFERENCES}

Amundsen, P. G. (1959). The diagnostic value of conventional radiological examination of the heart in adults. Acta radiol. (Stockh.), Suppl. 181.

Axén, O., Lindgren, E., and Malmström, G. (1946). Till kännedom om mätfelen vid Liljestrand-Lysholm-NylinZachrissons metod för hjärtvolymbestämning. Nord. Med., 29, 592.

Blasius, W. (1938). Herzmasse im Röntgenbild. Fortschr. Röntgenstr., 57, 567.

Broustet, P., Wangermez, C., Duhamel, J., Martin, P. L., Brichaud, H., and Fontanille, P. (1960). Étude comparative des résultats des mesures du volume cardiaque par la méthode de stratigraphie axiale transverse et les méthodes géométriques téléradiographiques. J. Radiol. Électrol., 41, 417. 
Comeau, W. J., and White, P. D. (1939). An evaluation of heart volume determinations by the Rohrer-Kahlstorf formula as a clinical method of measuring heart size. Amer. Heart J., 17, 158.

Domenet, J. G., Evans, D. W., and Howarth, F. H. (1963). Clinical experience with radiological determination of heart volume. Brit. Heart J., 25, 575.

Friedman, C. E. (1950). The residual blood of the heart. Amer. Heart J., 39, 397.

- (1951). Heart volume, myocardial volume and total capacity of the heart cavities in certain chronic heart diseases. Acta med. scand., Suppl. 257.

Fuchs, G., and Bayer, O. (1953). Eine neue Methode zur Bestimmung des Herzvolumens. Fortschr. Röntgenstr. 78, 709.

Geigel, R. (1914). Die klinische Verwertung der Herzsilhouette. Münch. Med. Wschr., 61, 1220.

Hubacher, O., and Nyffeler, M. (1946). Eine neue Methode zur Schlagvolumenbestimmung. Cardiologia (Basel), 11, 175.

Jonsell, S. (1939). A method for the determination of the heart size by teleroentgenography (a heart volume index). Acta radiol. (Stockh.), 20, 325.

Kahlstorf, A. (1932). U Uber eine orthodiagraphische Herzvolumenbestimmung. Fortschr. Röntgenstr., $45,123$.

Larsson, H., and Kjellberg, S. R. (1948). Rœntgenological heart volume determination with special regard to pulse rate and the position of the body. Acta radiol. (Stockh.), 29, 159.

Liljestrand, G., Lysholm, E., Nylin, G., and Zachrisson, C. G. (1939). The normal heart volume in man. Amer. Heart J., 17, 406.

Ludwig, H. (1939). Röntgenologische Beurteilung der Herzgrösse. Fortschr. Röntgenstr., $59,1$.

Musshoff, K., and Reindell, H. (1956). Zur Röntgenuntersuchung des Herzens in horizontaler und vertikaler Körperstellung. Dtsch. med. Wschr., 81, 1001.

Natvig, P. (1934). The volume of the heart in Müller's and Valsalva's tests. Acta radiol. (Stockh.), 15, 657.

Palmieri, G. G. (1929). Über meine Methode der plastischen Darstellung des Herzens am Lebenden ("Radioplastik"). Acta radiol. (Stockh.), 10, 127.

Plas, F., and Pallardy, G. (1963). Variations du volume cardiaque systolique et diastolique au cours et à la suite de l'effort. Presse méd., 71, 2436.

Rohrer, F. (1916/17). Volumbestimmung von Körperhöhlen und Organen auf orthodiagraphischem Wege. Fortschr. Röntgenstr., $24,285$.

Ruosteenoja, R., Linko, E., Lind, J., and Sollberger, A. (1958). Heart volume changes at rest and during exercise. Acta med. scand., 162, 263.

Snedecor, G. W. (1952). Query 92 . Biometrics, 8, 85.

Takahashi, S., and Shinozaki, T. (1954). Solidography of the heart. Acta radiol. (Stockh.), 41, 435.

Ungerleider, H. E., and Grubner, R. (1942). Evaluation of heart size measurements. Amer. Heart J., $24,494$. 